\section{Implicaciones y perspectivas del mix hídrico para el abastecimiento de agua potable en el sureste de España}

Water mix implications and perspectives for potable water supply in southeastern Spain

\author{
Miguel Borja Bernabé-Crespo \\ Universidad Autónoma de Madrid \\ Madrid, España \\ miguelb.bernabe@uam.es
}

iD ORCID: 0000-0001-7269-3270

\author{
Información del artículo \\ Recibido: 27 agosto 2020 \\ Revisado: 05 enero 2021 \\ Aceptado: 21 febrero 2021
}

$\begin{array}{ll}\text { ISSN } & 2340-8472 \\ \text { ISSNe } & 2340-7743 \\ \text { DOI } & 10.17561 / \text { AT.20.5714 }\end{array}$

(c) $\mathrm{CC}-\mathrm{BY}$

(c) Universidad de Jaén (España). Seminario Permanente Agua, Territorio y Medio Ambiente (CSIC)

\section{RESUMEN}

La Mancomunidad de Canales del Taibilla (MCT) realiza el abastecimiento de agua potable para la mayor parte del sureste de España, un área de clima mediterráneo semiárido con escasez estructural de agua. Con los datos de este organismo, se realiza un estudio del consumo de agua en el siglo XXI (2000-2019), en cuanto al volumen distribuido y la procedencia de cada recurso hídrico. Se analiza la evolución de los aportes para el mix hídrico de las aguas superficiales, trasvasadas y procedentes de la desalación. Se subraya que se ha diversificado la oferta del recurso y que es necesario mantenerla, paralelamente a la mejora de las redes de distribución y concienciación socioambiental.

PALABRAS CLAVE: Abastecimiento de agua, Trasvases de aguas,

Desalación, Medios semiáridos, Sureste de España.

\begin{abstract}
The Commonwealth of the Taibilla Channels (MCT) supplies drinking water to most of the Southeast of Spain, an area with a semi-arid Mediterranean climate with a structural shortage of water. With the data of this organism, a study of water consumption in the XXI century (2000-2019) is carried out, in terms of the distributed volume and the origin of each water resource. The evolution of the contributions to the water mix of surface water, transferred water and desalination are analyzed. It is emphasized that the supply of the resource has been diversified and that it is necessary to maintain it, in parallel with the improvement of the distribution networks and socio-environmental awareness.
\end{abstract}

KEYWORDS: Water supply, Water transfers, Desalination, Semiarid environments, Southeastern Spain. 


\section{Implicações e perspectivas da mistura hídrica para o abastecimiento de água potável no sudeste da Espanha}

\section{SUMÁRIO}

A Mancomunidade dos Canais do Taibilla (MCT) fornece água potável para a maior parte do sudeste da Espanha, uma área de clima mediterrâneo semi-árido com escassez estrutural de água. Com os dados deste órgão, é realizado um estudo do consumo de água no século XXI (2000-2019), em função do volume distribuído e da origem de cada recurso hídrico. É analisada a evolução das contribuições para a mistura hídrica das águas superficiais, transferidas e da dessalinização. Ressalta-se que a oferta do recurso tem sido diversificada e que é preciso mantê-la, paralelamente à melhoria das redes de distribuição e à conscientização socioambiental.

PALAVRAS-CHAVE: Abastecimento de água, Transferência de água, Dessalinização, Ambientes semi-áridos, Sudeste da Espanha.

Implications et perspectives du mix hydrique pour l'approvisionnement en eau potable dans le sud-est de l'Espagne

\section{RÉSUMÉ}

La Communauté des Canaux du Taibilla (MCT) fournit de l'eau potable à la majeure partie du sud-est de l'Espagne, une région au climat méditerranéen semi-aride avec une pénurie structurelle d'eau. À partir des données de cet organisme, une étude de la consommation d'eau au XXIe siècle (20002019) est menée, en termes de volume distribué et d'origine de chaque ressource en eau. L'évolution des contributions au mix hydrique des eaux de surface, transférées et issues du dessalement est analysée. Il est souligné que l'offre de la ressource a été diversifiée et qu'il est nécessaire de la maintenir, parallèlement à l'amélioration des réseaux de distribution et à la sensibilisation socio-environnementale.

MOTS-CLÉ: Approvisionnement en eau, Transferts d'eau, Dessalement,

Environnements semi-arides, Sud-est de l'Espagne.
Implicazioni e prospettive del mix idrico per l'approvvigionamento di acqua potabile nel sud-est della Spagna

\section{SOMMARIO}

La Associazione dei Canali del Taibilla (MCT) fornisce acqua potabile alla maggior parte del sud-est della Spagna, un'area con un clima mediterraneo semi-arido con una carenza idrica strutturale. Con i dati di questo ente viene condotto uno studio sul consumo di acqua nel XXI secolo (2000-2019), in termini di volume distribuito e origine di ciascuna risorsa idrica. Viene analizzata l'evoluzione dei contributi al mix idrico delle acque superficiali, trasferite e da dissalazione. Si sottolinea che l'offerta della risorsa è stata diversificata e che è necessario mantenerla, parallelamente al miglioramento delle reti di distribuzione e della consapevolezza socioambientale.

PAROLE CHIAVE: Approvvigionamento idrico, Trasferimenti d'acqua, Dissalazione, Ambienti semi-aridi, Sud-est della Spagna. 


\section{Introducción}

El abastecimiento de agua es una tarea de especial importancia para el correcto funcionamiento de los centros urbanos, donde se concentran grandes volúmenes de población en espacios reducidos. Este trabajo aborda el suministro de agua que realiza la Mancomunidad de Canales del Taibilla (en adelante, MCT) en su área de actuación, el sureste español, y continúa la labor ejercida para la caracterización del abastecimiento en la línea de otros autores ${ }^{1}$. Es, por tanto, un estudio de la distribución en alta, entendiéndose esta como la conducción desde la fuente de origen y su potabilización hasta la entrega a las empresas municipales.

Esta tarea de garantía de suministro hídrico es un asunto de vital importancia incluso en regiones con una pluviometría abundante, donde los problemas son causados por la contaminación de los recursos hídricos, como en Brasil $^{2}$, o debido a la deficiencia en las políticas públicas, como en México ${ }^{3}$. En regiones semiáridas y, por tanto, de escasez de recursos, como el sureste de España, el abastecimiento ha sido estudiado por numerosos expertos ${ }^{4}$ y la mayor parte de ellos destacan en los últimos tiempos un descenso en el volumen consumido, debido a las mejoras realizadas en la red de distribución. Los espacios con mayor densidad turística son los que encuentran mayor dificultad para asegurar un caudal permanente, por lo que precisan de una adecuada planificación turística e hidráulica ${ }^{5}$. La incidencia del cambio climático también prevé que el agua sea más escasa en esta región ${ }^{6}$, y que en el litoral mediterráneo las temperaturas sean más altas y las precipitaciones menos abundantes ${ }^{7}$, por lo que resulta imprescindible acometer trabajos que permitan lograr una seguridad hídrica ante un escenario cambiante. Esta hace referencia a "la disponibilidad de una cantidad suficiente de agua con la calidad adecuada para las personas, el funcionamiento de la economía y para los ecosistemas y, por un nivel aceptable de riesgos vinculados"

La conexión de cuencas mediante los trasvases de aguas, proyectados para paliar el déficit hídrico, han

\footnotetext{
1. Morales y Vera, 1989; Melgarejo y Molina, 2017.

2. Campos y Pacheco, 2018.

3. Mballa y Hernández-Espericueta, 2018.

4. Juárez, 2008; Bernabé-Crespo y Gómez-Espín, 2015; Morote, Hernández y Lois, 2019.

5. Vera, 2006; Rico, 2007; Baños, Vera y Díez, 2010.

6. Olcina, 2012

7. Olcina, Saurí y Vera, 2016.

8. Gómez, 2018, 8.
}

permitido el desarrollo regional en aquellas áreas donde el agua era escasa, necesaria y estratégica para el crecimiento socioeconómico. Por ejemplo, en California son la base del abastecimiento para uso potable y de riego ${ }^{9}$. Sin embargo, también causan tensiones entre las cuencas cedente y receptora, como sucede en el Acueducto Tajo-Segura ${ }^{10}$. Por su parte, el desarrollo de los llamados recursos no convencionales se ha extendido por aquellas regiones con características semiáridas, entre las que sobresale la desalación, ya que ha sido considerada como una adaptación al cambio climático ${ }^{11}, \mathrm{y}$ numerosos expertos han propuesto su aplicación en regiones áridas o semiáridas ${ }^{12}$, como las Islas Canarias, pioneras en España ${ }^{13}$, o el sureste de la Península Ibérica ${ }^{14}$. En esta región, la desalación es destacada como un seguro hídrico que permite una garantía de suministro en situaciones de necesidad ${ }^{15}$. Por otra parte, quedan dudas sobre si su adaptación es positiva o negativa, que pueda generar dependencia o aumento de precio ${ }^{16}$. Es lo que se conoce como "maladaptación", que puede incrementar la vulnerabilidad de un territorio al generar una sensación de agua ilimitada, o de suponer una huella de carbono mayor que otros recur$\operatorname{sos}^{17}$.

Otro de los recursos no convencionales que suscita mayor atención es el reciclaje de aguas o la regeneración de aguas residuales, por sus ventajas de ser un recurso local y un caudal permanente, aunque limitado ${ }^{18}$. Este está desarrollado en áreas semiáridas y utilizado preferentemente para riego, como en Túnez ${ }^{19}$, pero cada vez más se apuesta por su incorporación al ciclo urbano del agua ${ }^{20}$.

El área que ocupa este estudio reúne ciertas características que comprometen la seguridad en el abastecimiento. El sureste de la Península Ibérica (Mapa 1) es un área de carácter semiárido, situada entre el Cabo de Gata (Almería) al sur y el Cabo de la Nao (Alicante) al norte; y que se encuentra delimitada hacia el interior por la isoterma de más de $16^{\circ} \mathrm{C}$ de temperatura media anual

\footnotetext{
9. Bernabé-Crespo y Loáiciga, 2019.

10. Gil-Meseguer, Martínez-Medina y Gómez-Espín, 2018; Morote, Olcina y Rico, 2018.

11. Bates et al., 2008, 49 .

12. Cooley, Gleick y Wolff, 2006; Rutherfurd \& Finlayson, 2011; Loáiciga, 2015.

13. González-Morales y Ramón-Ojeda, 2019.

14. Olcina y Moltó, 2010; Morote, Rico y Moltó, 2017.

15. Bernabé-Crespo, Gil-Meseguer y Gómez-Espín, 2019.

16. March, 2015.

17. McEvoy \& Wilder, 2012; March, 2015.

18. Gil-Meseguer, Bernabé-Crespo y Gómez-Espín, 2019.

19. Hamrita y Rejeb, 2019.

20. Gleick, 2010.
} 
Mapa 1. El sureste de la Península Ibérica

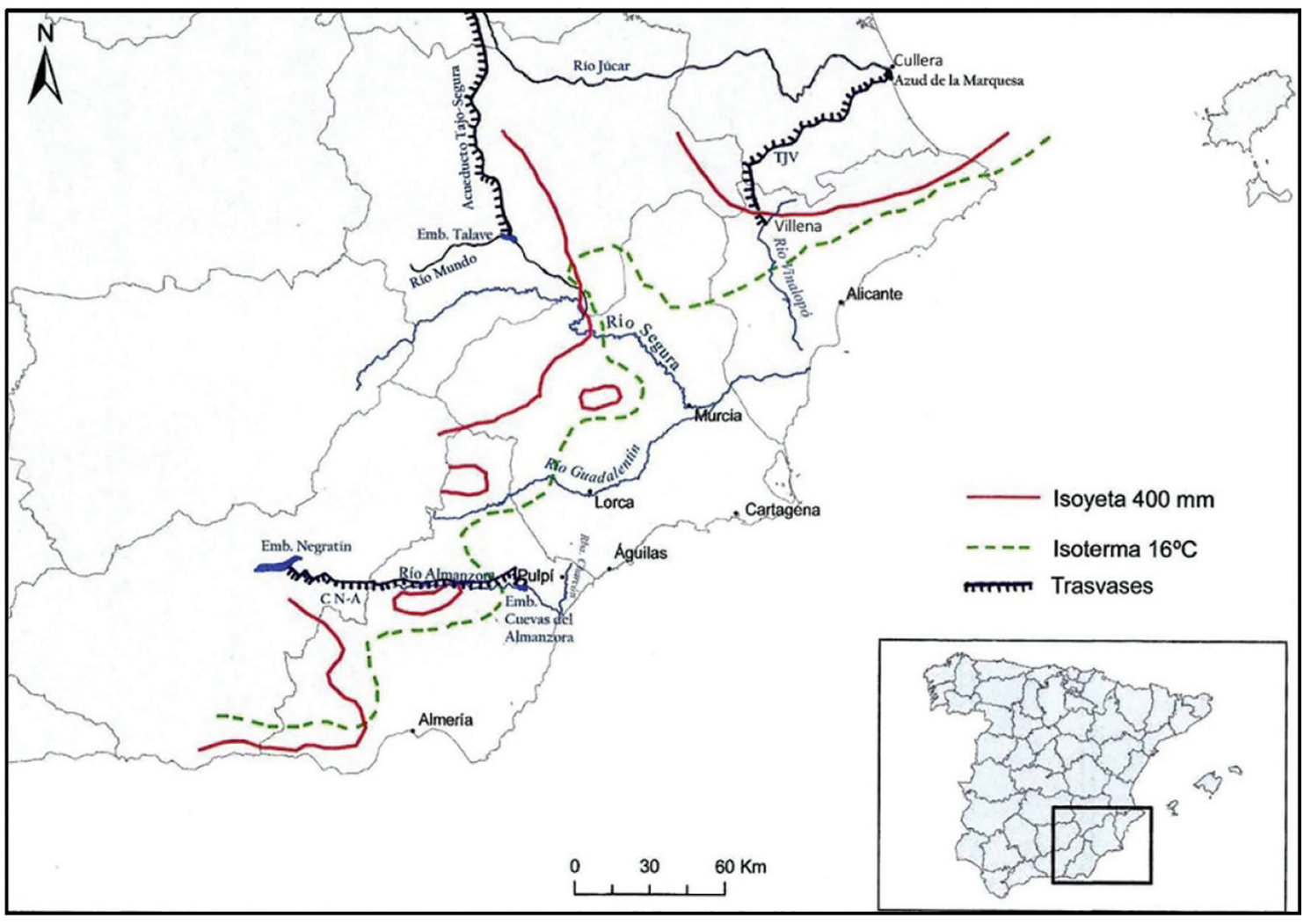

Fuente: Gil-Meseguer, Bernabé-Crespo y Gómez-Espín, 2017, 2.481.

y la isoyeta de menos de $400 \mathrm{~mm}$ de precipitación anual $^{21}$. La disposición del sistema bético, en dirección noreste-suroeste, resguarda a esta área a sotavento y origina un efecto foehn al erigirse como un abrigo orográfico frente a los vientos del oeste. Los cursos de agua son escasos y la mayoría son del tipo río-rambla, únicamente se podrían considerar ríos aquellos cursos permanentes cuya cabecera se ubica fuera de esta región (como sucede con el río Segura). Por sus características, en este territorio históricamente se han repetido las peticiones de traída de aguas, algunas de las cuales se han materializado en actuales trasvases ${ }^{22}$ como el del Júcar-Vinalopó (TJV), el Acueducto Tajo-Segura (ATS) o la Conexión Negratín-Almanzora (C N-A $)^{23}$.

Administrativamente, el sureste comprende la casi totalidad de las provincias de Murcia (Comunidad Autónoma de la Región de Murcia) y Almería (Andalucía), y la parte meridional de la provincia de Alicante (Comunidad Valenciana). La bonanza climática y la fertilidad de sus suelos, cuando estos tienen agua, han permitido que la región desarrolle un dinamismo económico en

\footnotetext{
21. Gil-Meseguer et al., 2014.

22. Gil-Meseguer, 2019.

23. Gil-Meseguer y Gómez-Espín, 2017.
}

diversos ámbitos, principalmente en la agricultura ${ }^{24} \mathrm{y}$ el turismo ${ }^{25}$. La MCT abastece a buena parte del sureste español, a un total de 80 municipios. En Murcia, lo hace a 43 de los 45 municipios con los que cuenta; a 35 de Alicante y a 2 de Albacete (Mapa 2).

En esta área, el crecimiento de la población en el siglo XXI ha crecido desde los 1.923 .891 habitantes en el año 2000 hasta los 2.528.656 que se cuentan en 2019 . Se observa que el crecimiento fue positivo hasta 2012 (un máximo de 2.553.278 habitantes), cuando comienza a descender hasta 2017, que anota un mínimo de 2.487.083 personas, para continuar creciendo en los últimos dos años (Gráfico 1). La mayoría de la población pertenece a la provincia de Murcia (57,7 \%) y a la de Alicante (42,2\%), y los dos municipios albaceteños de Férez y Socovos apenas suponen el 0,1\%.

Como antecedentes, en 1633 ya se tienen documentos sobre mancomunaciones entre Lorca, Totana, Murcia y Cartagena para emprender proyectos de traída de aguas desde los ríos Castril y Guardal ${ }^{26}$. Sin embargo, no sería hasta 1927 cuando se constituye la Mancomunidad de

\footnotetext{
24. Gómez-Espín, López-Fernández y Montaner, 2011.

25. Martínez del Vas, 2017

26. Mediavilla, 1928 .
} 
Mapa 2. Área de abastecimiento de la MCT

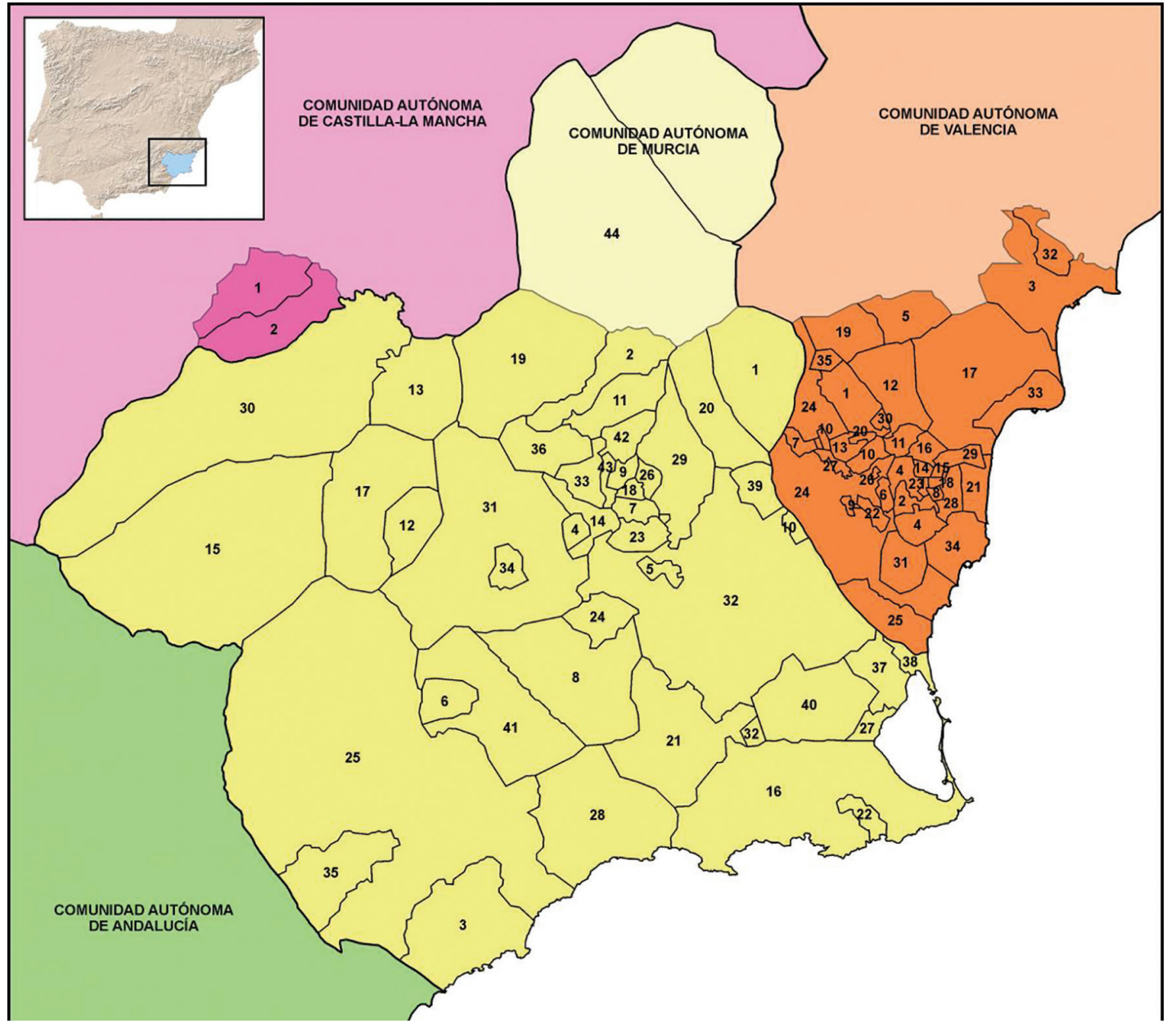

Fuente: datos suministrados por MCT (2020).

Gráfico 1. Evolución de la población en el área abastecida por la MCT (2000-2019)

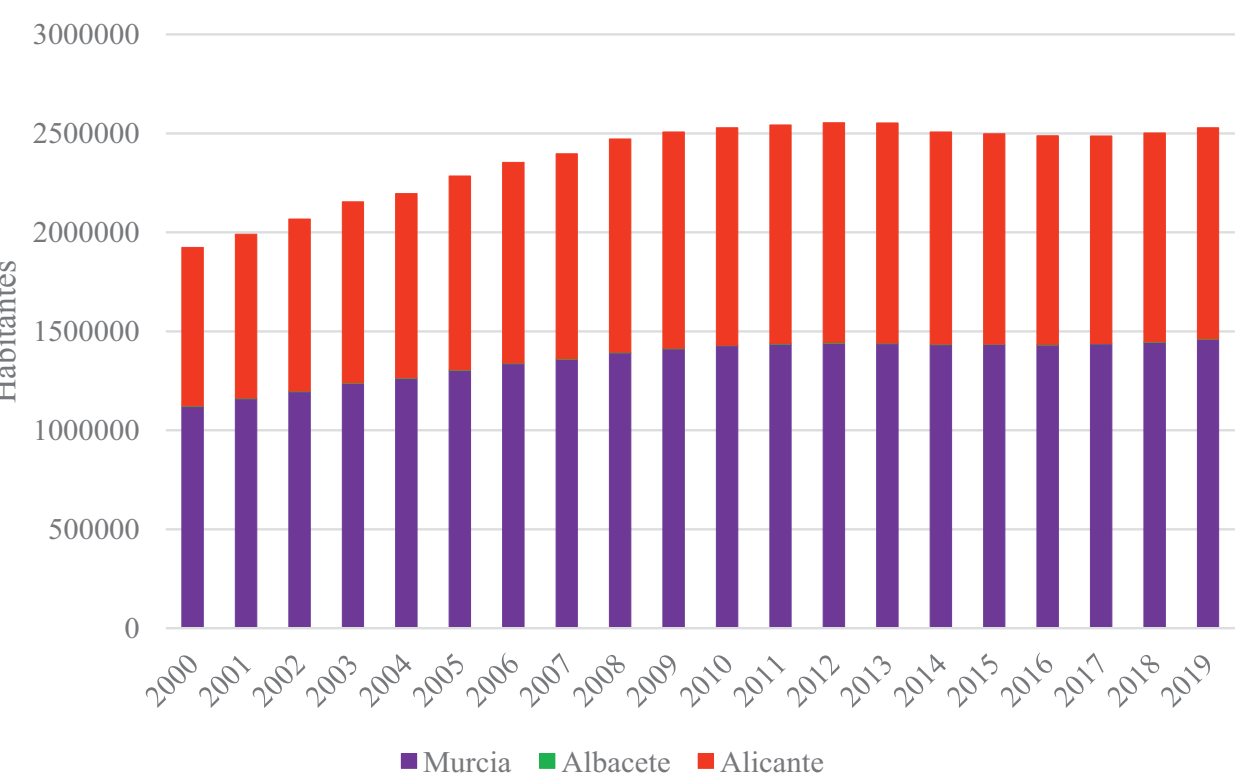

Fuente: padrón municipal, INE (Instituto Nacional de Estadística, 2020). 
Canales del Taibilla, con el cometido de traer el agua desde este río albaceteño y, como uno de sus principales objetivos, abastecer la base naval de Cartagena ${ }^{27}$. Pasaron años hasta resolver la financiación, hasta que en junio de 1932 comenzaron las obras que seguirían paralizándose con el tiempo. Durante la guerra civil continuaron realizándose planes para abastecer la base naval y, con su fin, la prioridad del abastecimiento a este emplazamiento militar hizo que las obras fueran declaradas como preferentes, de excepcional urgencia y de absoluta necesidad nacional, estando financiadas por el Estado en un $50 \%$ y el otro $50 \%$ por la mancomunidad por medio de operaciones de crédito con la garantía de los ayuntamientos ${ }^{28}$. Finalmente, en 1945 llegaron las aguas a la ciudad de Cartagena, celebrándose como un acontecimiento histórico. El suministro llegaría en los años siguientes a otras localidades sucesivamente, solicitando los municipios su abastecimiento mediante instancias. Así, en 1952 llegó a la Academia General del Aire y a San Javier, y en 1966 ya se abastecía a 46 municipios ${ }^{29}$. Por este entonces, ya se comenzaba a vislumbrar que el agua del Taibilla no sería suficiente para atender las necesidades de una población creciente. En 1933 ya se había planteado la traída de aguas desde el Tajo, por parte de don Manuel Lorenzo Pardo en su Plan Nacional de Obras Hidráulicas ${ }^{30}$, pero en 1967 se realizó el Anteproyecto General de Aprovechamiento conjunto de los recursos hidráulicos del centro y sureste de España: Complejo Tajo-Segura, el antecedente más directo del Acueducto Tajo-Segura (ATS), que finalmente entró en funcionamiento en 1979. La oferta de recursos se ampliaría más recientemente con la instalación de una red de desaladoras mediante el Programa A.G.U.A., la primera de ellas en Alicante en 2003.

\section{Objetivos y metodología}

El estudio aplica la metodología propia del Análisis Geográfico Regional, en la cual se han distinguido varias fases. En primer lugar, la revisión bibliográfica sobre el estado de la cuestión y la elaboración del marco teórico. El trabajo de campo ha sido extensivo y se ha llevado a cabo la visita a las instalaciones de la MCT para la recogida de datos y la visita a las plantas desaladoras, tanto de MCT como ACUAMED (Sociedad Estatal Aguas de las Cuencas Mediterráneas). El posterior trabajo de gabinete

\footnotetext{
27. Vera y Morales, 1989.

28. Nieto, 2013.

29. Bernabé-Crespo, 2020.

30. Gil-Meseguer, Bernabé-Crespo y Gómez-Espín, 2017.
}

ha consistido en el análisis cuantitativo de los datos, combinado con el cualitativo para caracterizar la situación del abastecimiento de agua en alta en el sureste de España. En ellos se incluye el cálculo de la desviación típica o estándar $(\sigma)$, hallada según la raíz cuadrada de la varianza:

$$
\sqrt{\frac{\sum(\mathrm{Xi}-\mathrm{X})^{2}}{\mathrm{n}-1}}
$$

Sirve esta para establecer el valor que determina el rango típico ( $\sigma$ sumada a la media; $\sigma$ restada a la media). Los valores fuera de este rango son excepcionalmente inusuales. La variable utilizada es el consumo en alta (el que la MCT distribuye a los distintos ayuntamientos o empresas), desglosado según su procedencia: aguas superficiales (río Taibilla y aguas provenientes del ATS), aguas desaladas (tanto de las desaladoras propias como de las que establecen acuerdos con la MCT) y un conjunto de otras aguas, entre las que se incluyen los contratos de cesiones de derechos al uso del agua. También se tiene en cuenta la evolución de la población para realizar el cálculo del consumo per cápita (datos obtenidos del Instituto Nacional de Estadística). Estas permiten conocer la tendencia del origen del suministro y poder establecer unas conclusiones en cuanto a la diversificación de la oferta de recursos. Se señala que la MCT abastece agua para consumo potable, por lo que otros usos del agua (como el riego) están excluidos de este análisis.

El periodo escogido (2000-2019) abarca el siglo XXI hasta los datos disponibles en la actualidad, y representa un buen ejemplo de la evolución de las distintas fuentes de abastecimiento. Entre los hitos más reseñables, destaca el inicio de la desalación en 2003, por lo que se puede estudiar su trayectoria y la labor que ha realizado dentro del suministro del agua. Igualmente, si bien el ATS entró en funcionamiento en 1979, ha sido en el siglo XXI cuanto se ha visto más cuestionado y se llegaron a paralizar los envíos para consumo humano durante varios meses, entre noviembre de 2017 y mayo de 2018 (ambos incluidos).

El objetivo de este estudio es analizar la evolución de los recursos hídricos de la MCT según su procedencia y valorar su tendencia, para explicar qué repercusiones ha tenido y cuál es el escenario próximo que puede encontrarse. Se comparan la primera década del siglo XXI con la segunda para apreciar las diferencias, permitiendo establecer unas tendencias futuras y unas recomendaciones para asegurar la garantía de suministro a un espacio de alta densidad poblacional y económica. 


\section{Resultados}

En el total del área abastecida por la MCT, el volumen distribuido se situaba en el 2000 en $198.422 .547 \mathrm{~m}^{3}$. Su ascenso fue continuo hasta el 2005, cuando marcó un máximo de $227.284 .806 \mathrm{~m}^{3}$. La tasa de incremento promedio para el periodo 2000-2005 fue del $+2,75 \%$ (es decir, de media, cada año aumentó el consumo total un $2,75 \%$ ). Los años 2005, 2006 y 2007 presentaron un consumo estabilizado, pero desde 2005 se inicia una reducción prolongada del consumo hasta el mínimo de 2014, con $183.174 .411 \mathrm{~m}^{3}$. En este periodo, la tasa de incremento fue de un promedio de $-2,94 \%$ (cada año se reducía el consumo un 2,94 \%). Al ser mayor la magnitud absoluta del incremento (negativo) y su mayor cantidad de años, en 2014 se consumían $15.248 .136 \mathrm{~m}^{3}$ menos de agua que en el 2000, en un área que aglutinaba 583.101 habitantes más, por lo que se deduce que se ha reducido el consumo per cápita y se han llevado a cabo esfuerzos en la eficiencia hídrica. Desde 2014, el consumo se recupera hasta alcanzar en el último registro disponible los 197.948.297 $\mathrm{m}^{3}$, lo que supone una tasa de incremento promedio del $+1,57 \%$, por lo que nos encontramos ante una etapa de reactivación del consumo, aunque con menor vigorosidad que en la de anterior auge (Gráfico 2).

Atendiendo a la procedencia de los recursos hídricos, en el 2000 el principal aportador del mix hídrico eran las aguas trasvasadas desde el Tajo, que suponían el 72,93 \% del total. En 2003 entró en funcionamiento la primera desaladora, que apenas llegó a producir el $2,34 \%$ del total. Sin embargo, la desalación ha llegado a suponer el 47,62 \% del total en 2018 (Gráfico 3).

Gráfico 2. Evolución del volumen de agua distribuido por la MCT (2000-2019)

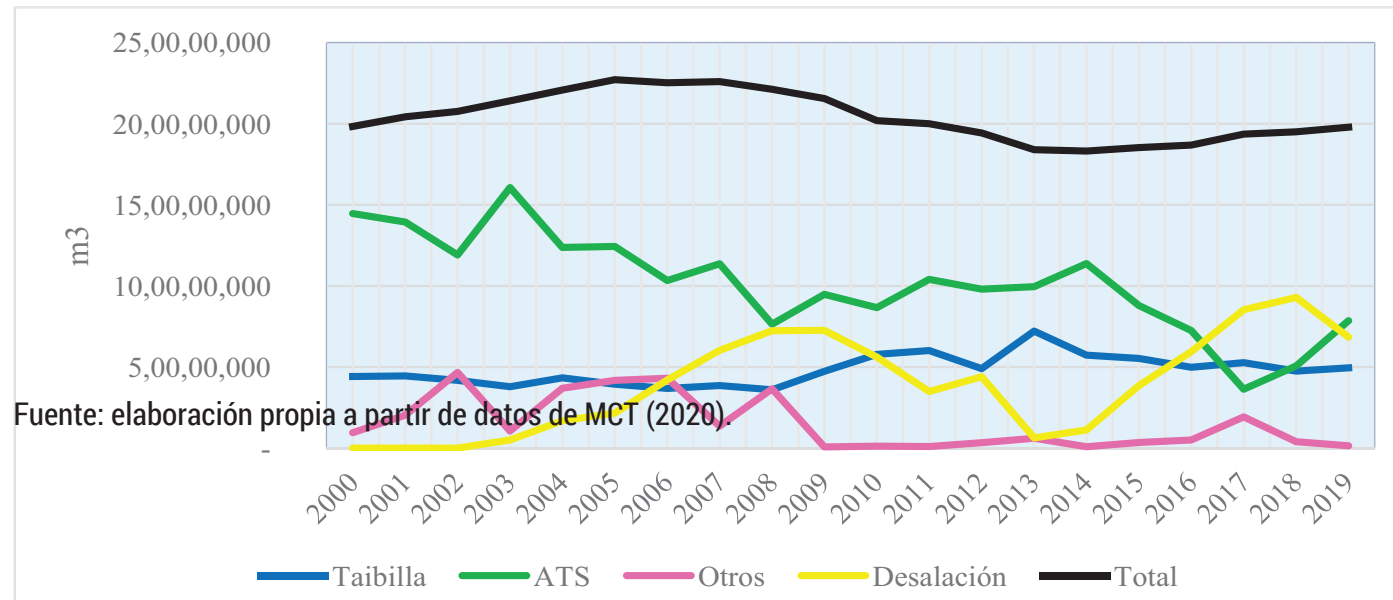

Gráfico 3. Evolución del origen de los recursos hídricos en el mix de la MCT (2000-2019)

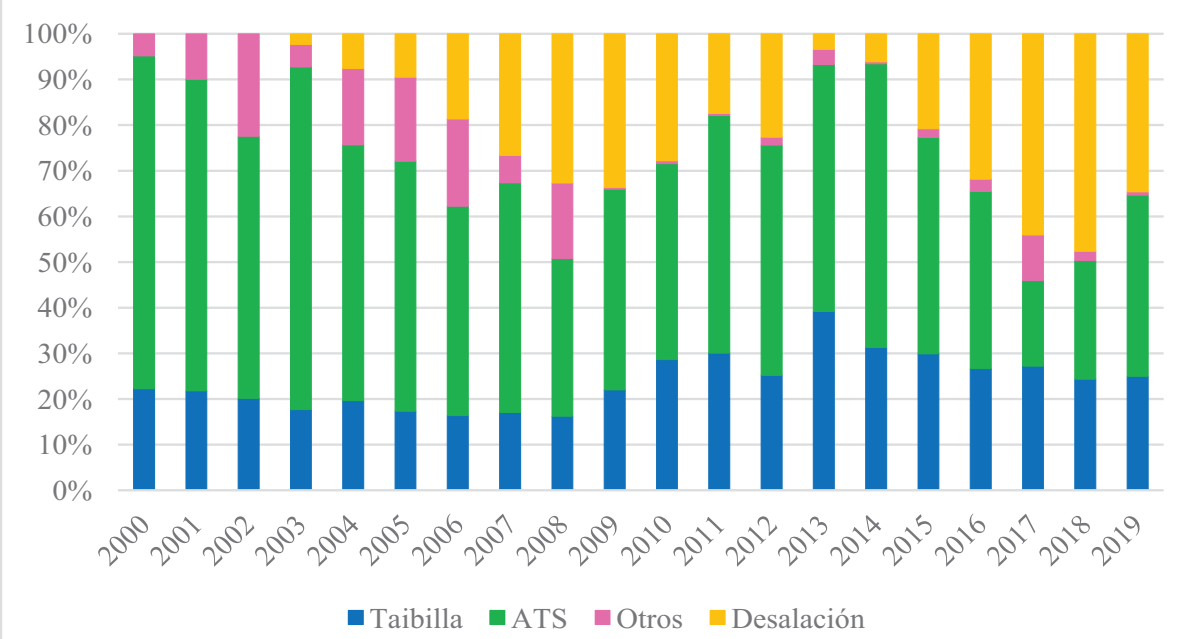

Fuente: elaboración propia a partir de MCT (2020). 
Se aprecia un cambio en el papel de piedra angular del abastecimiento: la hegemonía del ATS desde el 2000 se redujo en 2006 a la mitad ( $45,88 \%$ del total), y recientemente la comparte con la desalación, cuya relación es variable y determinada por los periodos de sequía.

Las aguas superficiales de la MCT son las procedentes del río Taibilla (Albacete), originario trasvase de aguas que dio nombre a la mancomunidad; las trasvasadas desde el río Tajo (Guadalajara) mediante el ATS; y las llama- das "otras aguas", que incluyen recursos extraordinarios procedentes de pozos de sequía, o mediante contratos de cesiones de derechos con otros usuarios.

El río Taibilla (Figura 1) ha aportado de media unos $48.061 .879 \mathrm{~m}^{3}$; siendo la media superior en la segunda década que en la primera (Gráfico 4). El mínimo de aportes se situó en 2008 con $35.950 .551 \mathrm{~m}^{3}$, y su máximo en 2013 con $72.113 .547 \mathrm{~m}^{3}$. Su desviación típica $(\sigma)$ es de $8.988 .494 \mathrm{~m}^{3}$ (equivalente a un $18,70 \%$ de su apor-

Figura 1. Pantano del Taibilla (Albacete)

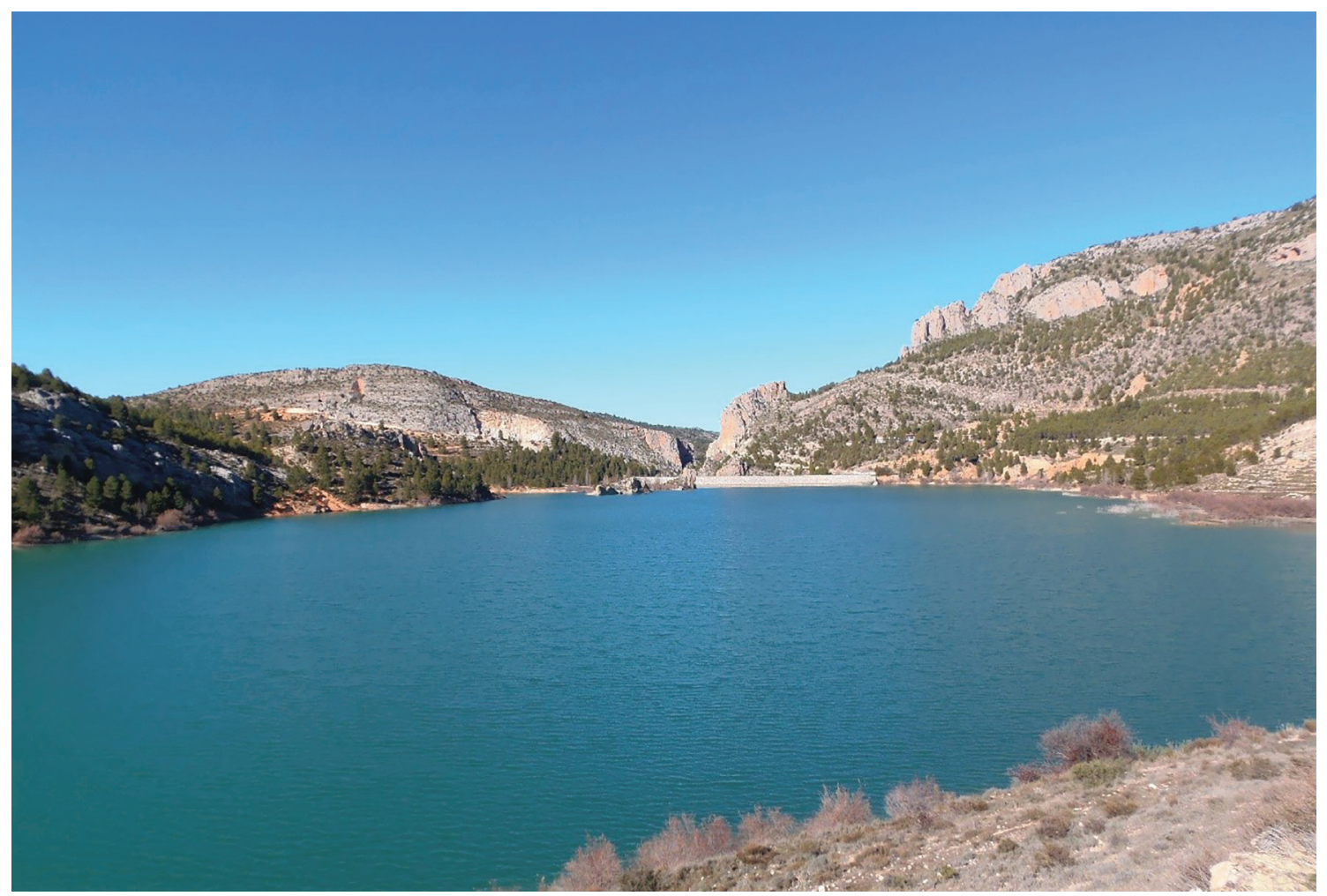

Fuente: autor.

Gráfico 4. Aportaciones del río Taibilla en el mix hídrico de la MCT (2000-2019)

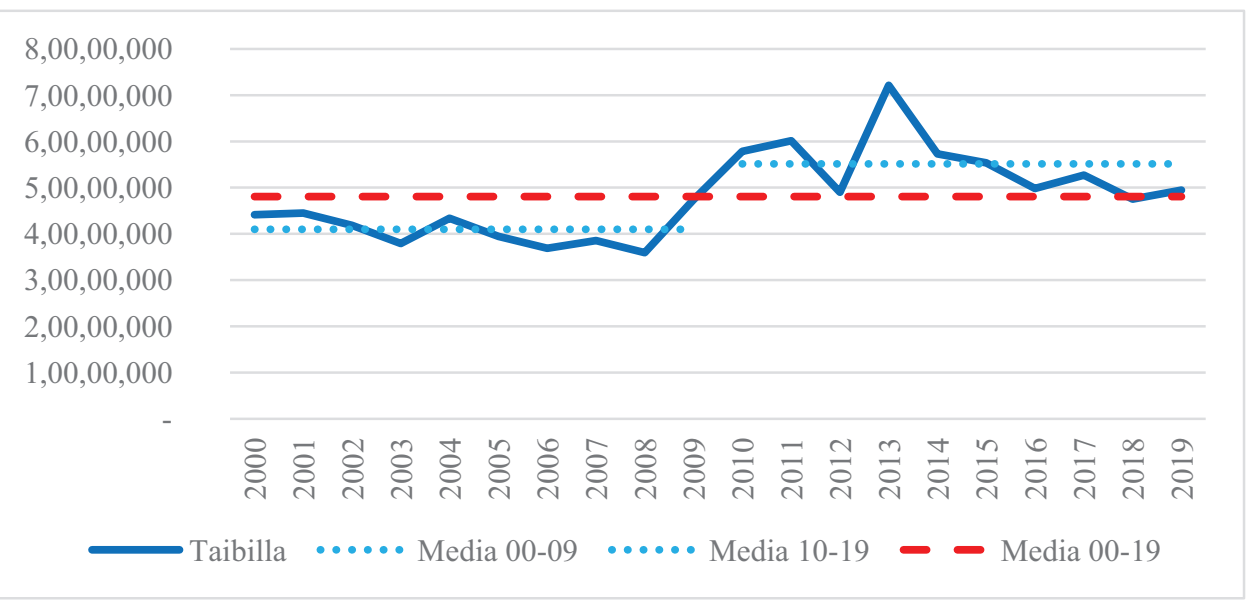

Fuente: elaboración propia a partir de MCT (2020). 
tación media), por lo que el rango típico se sitúa entre 57.050.373 y 39.073.385. Por tanto, los bienios 20102011 y 2013-2014 fueron inusualmente de más aportes; mientras que 2003 y el trienio 2006-2007-2008, años de excepcionales reducciones.

Las aguas de la cabecera del Tajo empezaron a llegar a la cuenca del Segura en 1979, a través del embalse de Talave (Figura 2), y desde entonces se ha configurado como pieza clave del abastecimiento surestino. En el siglo XXI, ha aportado de media unos $101.426 .507 \mathrm{~m}^{3}$, aunque en la última década los aportes han sido considerablemente inferiores a los años 2000-2009 (Gráfico 5). El mínimo de aportes se ha contabilizado en el año 2017, con $36.298 .995 \mathrm{~m}^{3}$, debido a la sequía que motivó la paralización de los envíos desde noviembre de 2017 hasta mayo de 2018, ambos incluidos. El máximo lo alcanzó

Figura 2. Embalse de Talave, que recibe las aguas del Tajo en la cuenca del Segura

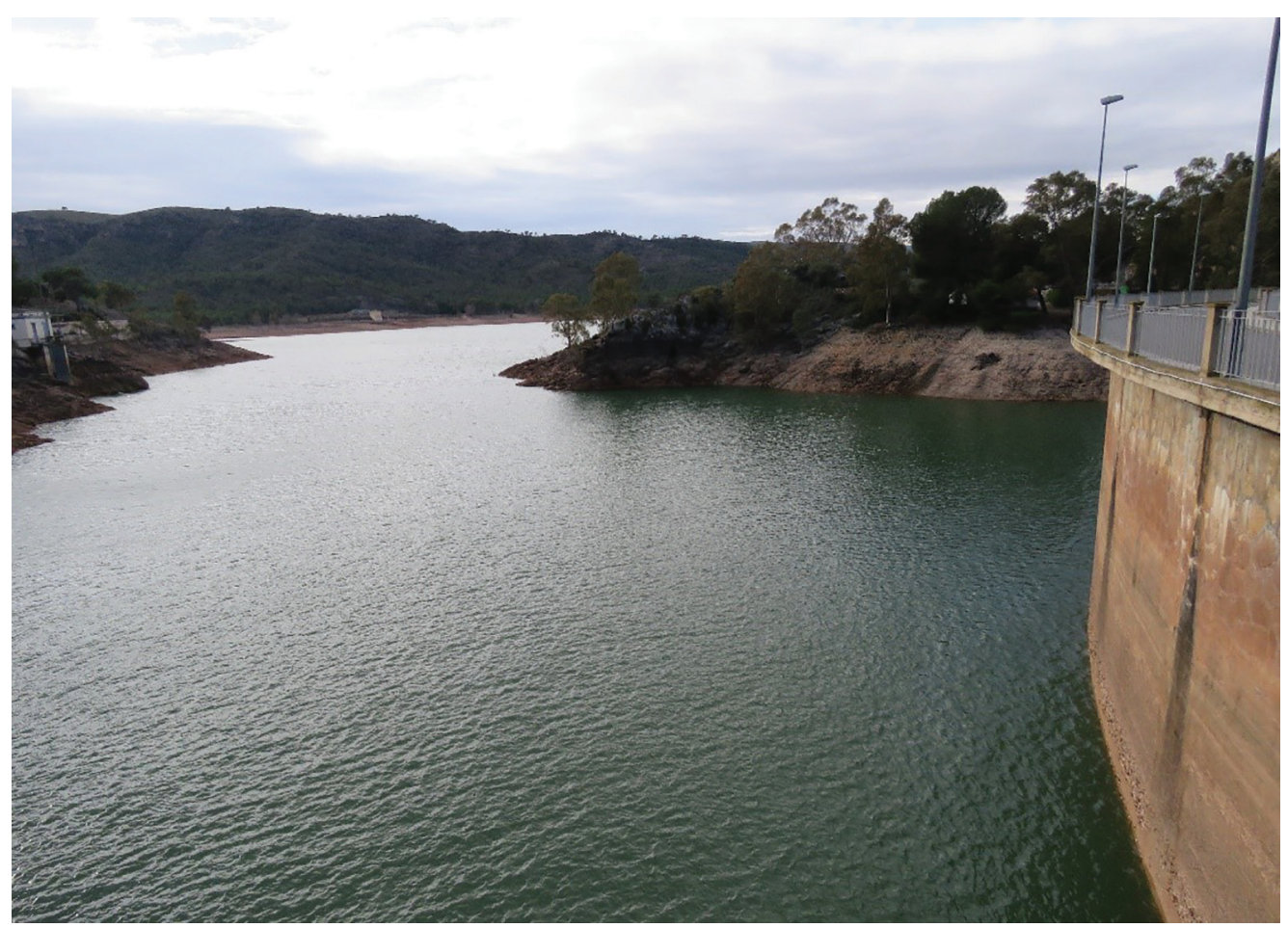

Fuente: autor.

Gráfico 5. Aportaciones del ATS en el mix hídrico de la MCT (2000-2019)

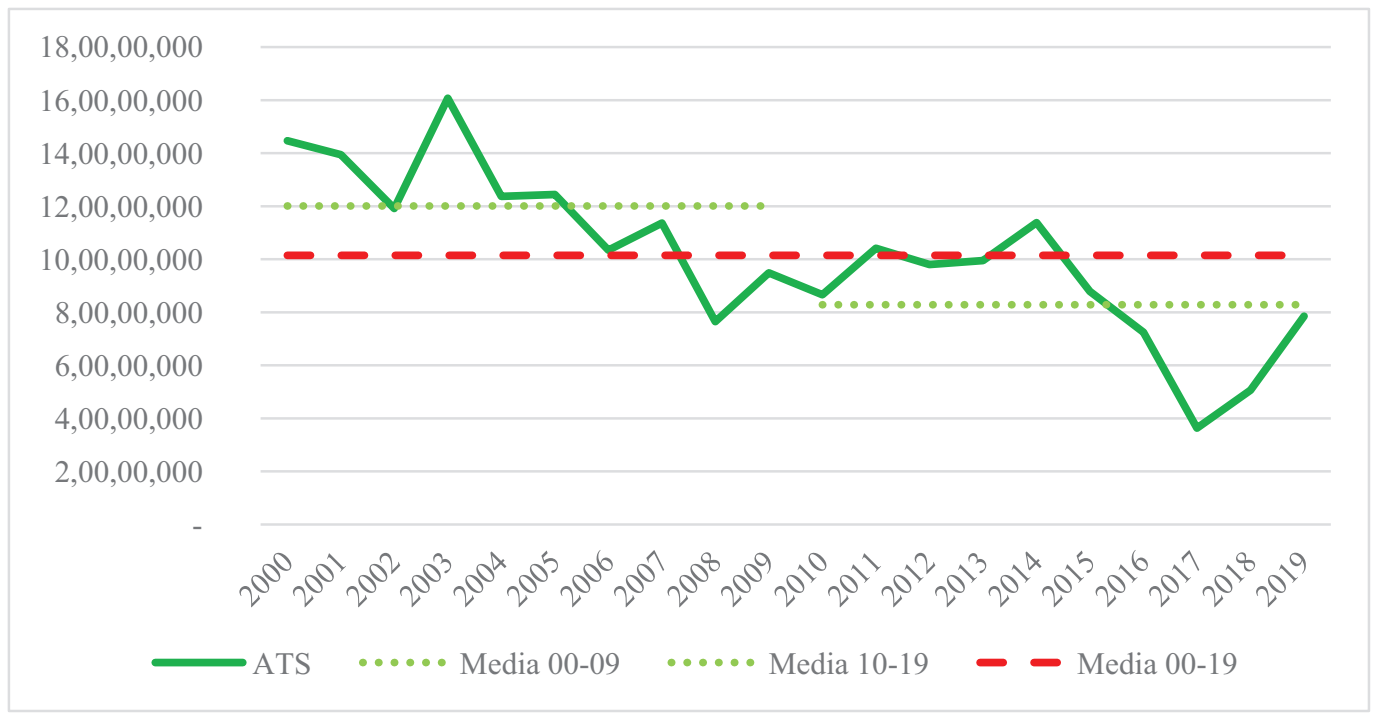

Fuente: elaboración propia a partir de MCT (2020). 
en 2003 con $160.714 .500 \mathrm{~m}^{3}$. Ello ocasiona una desviación típica $(\sigma)$ de $29.796 .727 \mathrm{~m}^{3}$, lo que supone el 29,38\% de la media. Su alta desviación indica un intervalo de confianza amplio, que oscila entre los 131.223.234 y 71.629.781; por lo que pueden considerarse como anormales los años 2000, 2001 y 2003 por ser superiores; y 2017-2018 por ser inferiores.

Por último, la categoría de "otras aguas" representa un porcentaje residual del mix hídrico de la MCT, y que solo se emplea en momentos puntuales de necesidad. Es por ello que estos valores son teóricos y, aunque no se ajustan a un escenario de realidad, sí sirven como guía para interpretar su evolución. De media, se han contabilizado un $15.275 .127 \mathrm{~m}^{3}$ de aportaciones al año, observándose que fueron superiores en la primera década a la segunda (Gráfico 6). El mínimo se dio en 2009, con apenas $724.230 \mathrm{~m}^{3}$, y el máximo en 2002, con $46.618 .790 \mathrm{~m}^{3}$. La notable diferencia se traduce en una desviación típica $(\sigma)$ de $15.950 .483 \mathrm{~m}^{3}$ (equivalente del 104,42\%), una distribución anormal, por lo que no existe un intervalo de confianza, ya que cada año depende de la coyuntura.

Las aguas procedentes de la desalación comenzaron a participar en el mix hídrico en 2003, cuando entró en funcionamiento la planta desaladora de Alicante I. Desde entonces, han suministrado de media $39.405 .185 \mathrm{~m}^{3}$, elevándose en la última década respecto de la primera (Gráfico 7). Si obviamos 2003, el año de inicio, el mínimo

Gráfico 6. Otras aportaciones de aguas en el mix hídrico de la MCT (2000-2019)

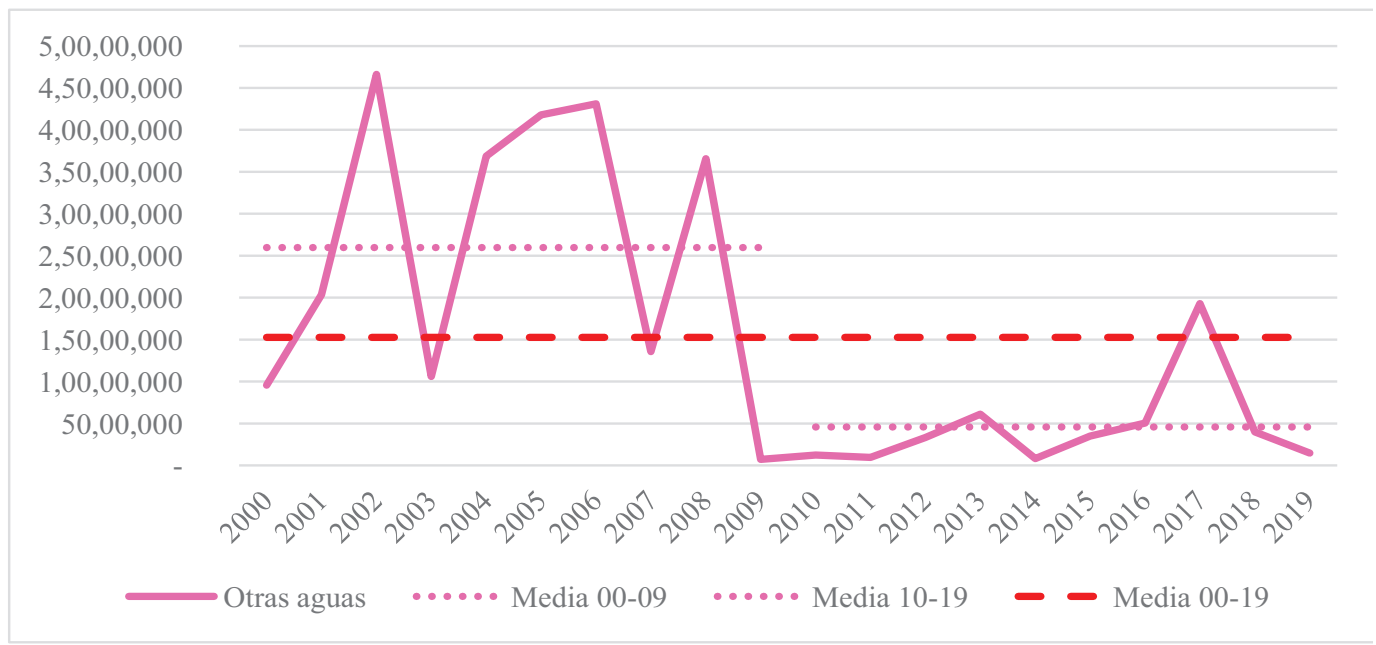

Fuente: elaboración propia a partir de MCT (2020).

Gráfico 7. Aportaciones de agua desalada en el mix hídrico de la MCT (2000-2019)

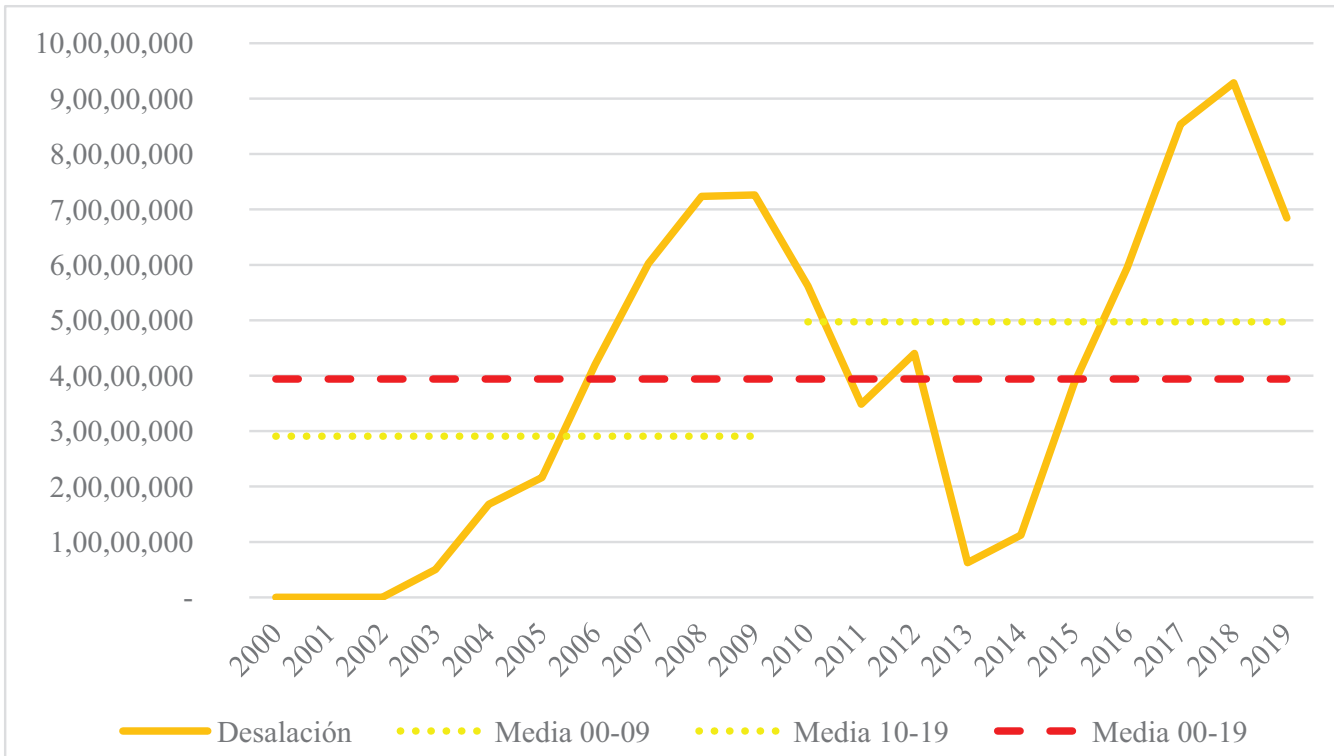

Fuente: elaboración propia a partir de MCT (2020). 
se encontraría en 2013, con solo 6.273.140 m³ y el máximo en 2018 , con $92.867 .715 \mathrm{~m}^{3}$. La desviación típica $(\sigma)$ resultante es de 25.540 .431 (el 64,81 \% de la media), lo que confirma que sus aportaciones son muy variables y solo entran en funcionamiento cuando la situación lo requiere. Ello resulta en un intervalo de confianza muy amplio, entre 64.945.615 y 13.864.754, que solo deja como inusualmente altos los periodos de sequía en el sureste: bienio 2008-2009 y trienio 2017-2018-2019; e inusuales bajos a 2013-2014.

Los caudales de agua desalada pueden tener, a su vez, distintas procedencias. La primera división es la titula- ridad: la MCT posee cuatro plantas desaladoras (Alicante I y II; San Pedro I y II), que son las que principalmente abastecen de agua desalada cuando la situación lo requiere. Pero, además, existen otras plantas desaladoras (cuya titularidad es de ACUAMED) que pueden proveer de este recurso a la MCT en situaciones excepcionales, mediante la firma de acuerdos y convenios. Estas son las de Valdelentisco (situada entre Cartagena y Mazarrón), la de Águilas-Guadalentín, y la de Torrevieja (Figura 3).

El Gráfico 8 muestra la producción de cada una de estas plantas para el mix hídrico de la MCT, distinguiendo en tonos fríos las de MCT y cálidos las de ACUAMED.

Figura 3. Bastidores de ósmosis inversa en la desaladora de Torrevieja (Alicante)

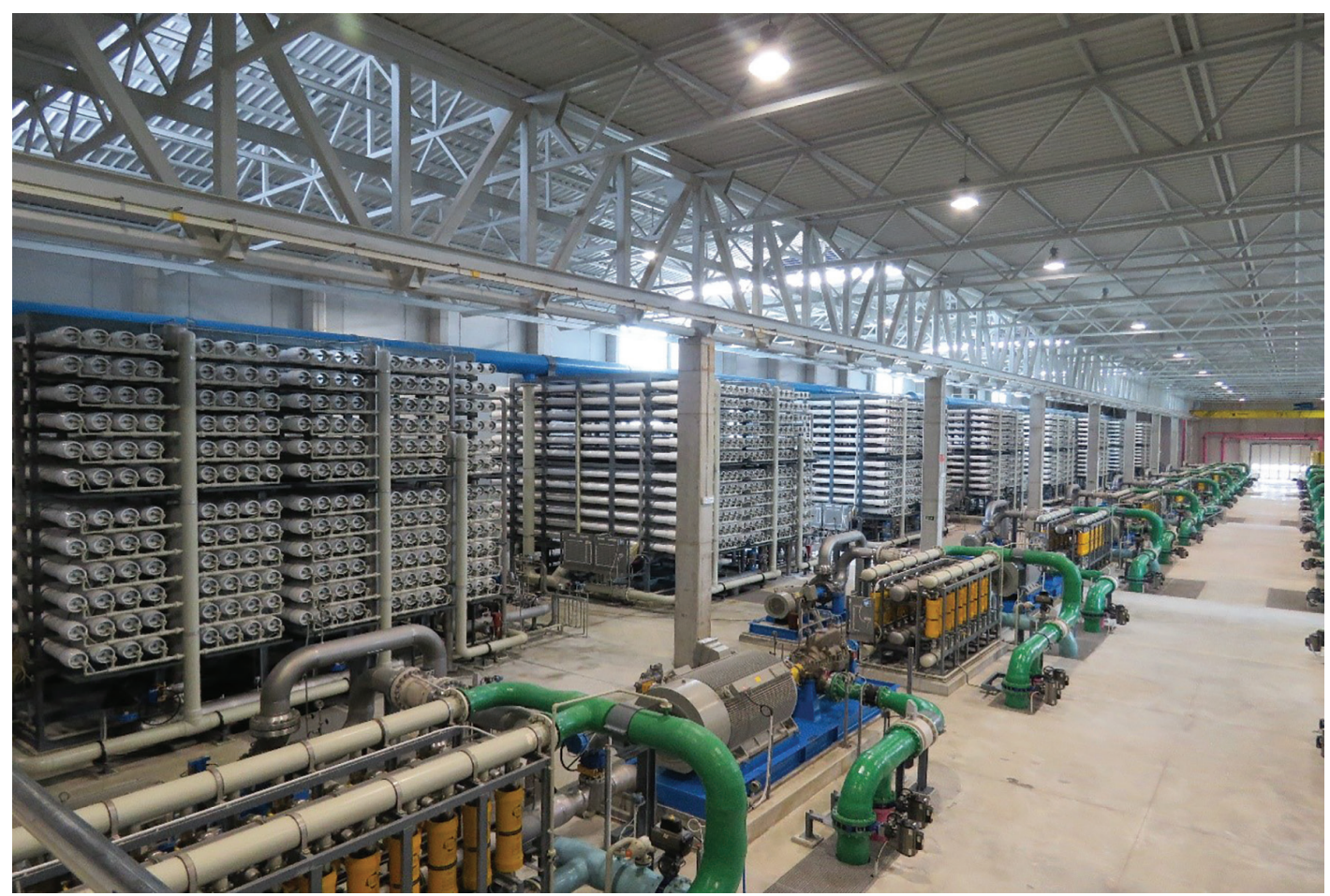

Fuente: autor.

Gráfico 8. Producción de agua desalada en el mix hídrico de la MCT por planta desaladora (2003-2019)

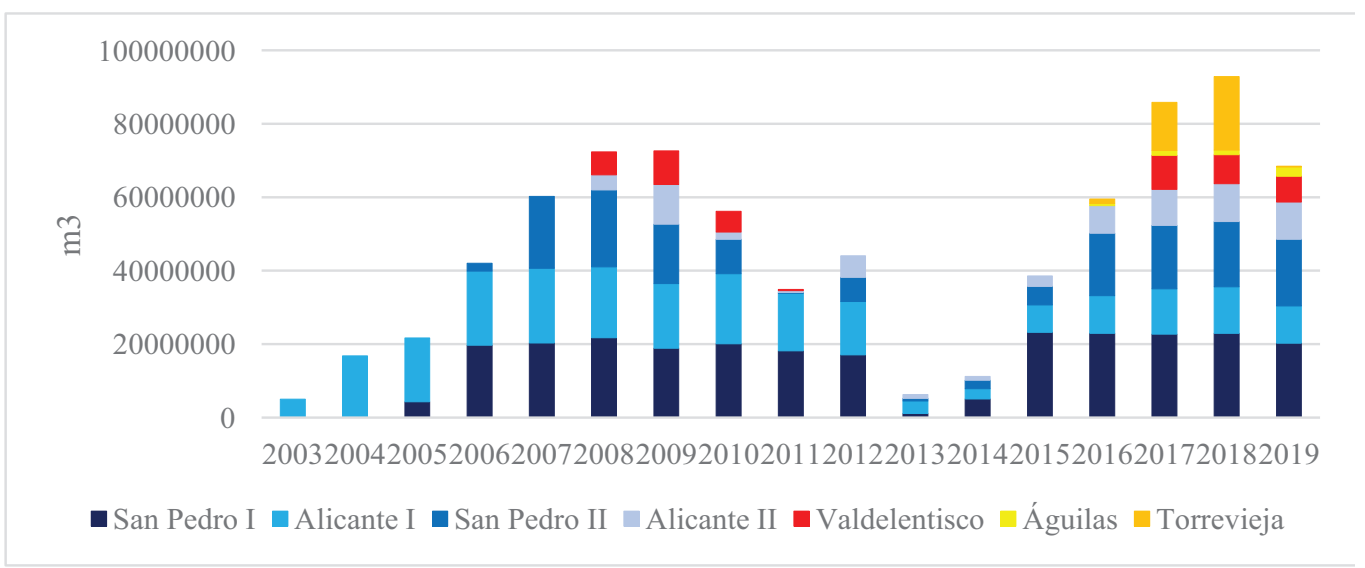

Fuente: elaboración propia a partir de MCT (2020). 
San Pedro I es la desaladora que más agua ha aportado, con 17.223.900 $\mathrm{m}^{3}$ de media; siguiéndole Alicante I con 13.238.790 m³ San Pedro II con $10.957 .806 \mathrm{~m}^{3}$; y, por último, Alicante II con $5.493 .378 \mathrm{~m}^{3}$. El año que más agua produjeron las desaladoras de la MCT fue 2008, pero realmente fue en 2018 cuando se alcanzó el máximo de producción desalada, al sumar los aportes de las desaladoras de ACUAMED. De aquí se desprende que, por encima de los 60 millones de $\mathrm{m}^{3}$, la MCT necesita recurrir a las desaladoras de ACUAMED para garantizar su abastecimiento. Entre ellas, la que más caudal ha aportado es Torrevieja, con una media de $8.663 .103 \mathrm{~m}^{3}$ (en cuatro años de suministro), le siguen Valdelentisco con $6.507 .721 \mathrm{~m}^{3}$ de media (siete años de suministro); y Águilas-Guadalentín, $1.408 .248 \mathrm{~m}^{3}$ de media (cuatro años de suministro).

\section{Discusión}

En el espacio del sureste se concentra una prominente actividad turística que hace difícil constatar la po- blación real que utiliza los recursos hídricos puestos a disposición por la MCT. Además, han de tenerse en cuenta otros recursos propios de agua que puedan aprovechar los diferentes ayuntamientos y empresas municipales de distribución de aguas, aunque estos son casi testimoniales. Por tanto, es la MCT el ente responsable de garantizar la seguridad hídrica y de abastecer a una población permanente de más de 2,5 millones de personas, además de la industria asociada. Si se tiene en cuenta esta distribución en alta se puede observar que, en el siglo XXI, tras periodos de aceleración y desaceleración del consumo, el volumen consumido en $2019\left(197.948 .297 \mathrm{~m}^{3}\right)$ es incluso menor que en el 2000 $\left(198.422 .547 \mathrm{~m}^{3}\right)$, al contrario que el crecimiento de la población, que ha aumentado en el mismo periodo en 604.765 personas más. Estableciendo un dato de consumo per cápita teórico, este ha descendido desde los $103 \mathrm{~m}^{3} /$ habitante del 2000 hasta los $78 \mathrm{~m}^{3} /$ habitante en 2019 (Tabla 1).

El cálculo del consumo per cápita teórico muestra que se ha aumentado la eficiencia del recurso en la re-

Tabla 1. Evolución de la relación entre habitantes y volumen de agua distribuida en alta por la MCT (2000-2019)

\begin{tabular}{llcc}
\hline Año & Habitantes & Volumen distribuido $\left(\mathbf{m}^{3}\right)$ & Consumo per cápita $\left(\mathbf{m}^{3} /\right.$ habitante $)$ \\
\hline 2000 & 1.923 .891 & 198.422 .547 & 103 \\
2001 & 1.990 .673 & 204.306 .125 & 103 \\
2002 & 2.067 .207 & 207.601 .716 & 100 \\
2003 & 2.154 .708 & 214.243 .085 & 99 \\
2004 & 2.196 .198 & 220.782 .853 & 101 \\
2005 & 2.285 .002 & 227.284 .806 & 99 \\
2006 & 2.353 .200 & 225.382 .449 & 96 \\
2007 & 2.396 .799 & 226.032 .617 & 94 \\
2008 & 2.472 .040 & 221.319 .721 & 90 \\
2009 & 2.507 .671 & 215.560 .249 & 86 \\
2010 & 2.528 .714 & 201.934 .924 & 80 \\
2011 & 2.542 .146 & 200.080 .643 & 79 \\
2012 & 2.553 .278 & 194.394 .710 & 76 \\
2013 & 2.553 .080 & 184.026 .747 & 72 \\
2014 & 2.506 .992 & 183.174 .411 & 78 \\
2015 & 2.498 .607 & 185.315 .718 & 78 \\
2016 & 2.488 .288 & 186.876 .886 & 74 \\
2017 & 2.487 .083 & 193.652 .963 & 78 \\
2018 & 2.502 .625 & 195.032 .493 & 797.948 .297 \\
2019 & 2.528 .656 & & 96 \\
\hline
\end{tabular}

Fuente: elaboración propia. 
gión del sureste español, y que se han acometido labores de mejora en el rendimiento de la red y reducido las pérdidas de agua. De igual manera, que la sociedad está concienciada y que las campañas de sensibilización han tenido un efecto sobre la población, motivándola a ejercer un ahorro del agua. Además, es necesario añadir el consumo realizado por los turistas, no contabilizados en la población permanente. En un área donde la llegada de turistas se ha incrementado desde el 2000 hasta la irrupción de la crisis económica de 2008, el conseguir bajar paulatinamente el consumo per cápita, aun recibiendo mayor número de turistas, es un logro de la sociedad y de los encargados del abastecimiento. Sin embargo, preocupa que desde 2013 esta cifra se encuentre en aumento, aunque esta puede deberse a la vuelta de turistas una vez superada la crisis económica. Lo importante es que no continúe creciendo por encima de niveles precrisis, y que se mantengan los esfuerzos por reducir el consumo aún más, es decir, continuar en la senda del ahorro y la eficiencia.

En cuanto a la procedencia de los recursos, se aprecia un cambio de notable calado en la composición del mix hídrico de la MCT: en la primera década estaba compuesto en su mayoría por el caudal procedente del trasvase Tajo-Segura, con un considerable aporte del río Taibilla; mientras que en la segunda década se ha diversificado la oferta del recurso, haciendo que las aguas trasvasadas y la desalación compitan por ser el mayor abastecedor según el año, además del aporte más regular del Taibilla. De esta manera, el Taibilla contribuye entre un 16 y un $39 \%$ del total, con una media al alza; el ATS entre el 19 y el $75 \%$, con una media a la baja; la desalación desde un 3 al 48 \% y una media al alza; y otros aportes desde ser prácticamente inexistentes (0,34 \%) a más del $20 \%$ (Tabla 2$)$.
El río Taibilla es la fuente más constante de suministro, por ser un cauce permanente de agua y vinculado a la cuenca del Segura, aunque este es insuficiente y depende de la precipitación recibida, pues no llega a representar más del $40 \%$ en sus años más húmedos. Las aguas del trasvase Tajo-Segura han sufrido las controversias político-territoriales que, sumadas a las sequías, han convertido a esta fuente en más variable de lo que solía ser antaño. En este sentido, es necesario una doble responsabilidad: para asumir que los periodos de sequía pueden ser más recurrentes y que el caudal trasvasado tienda a ser menor; y la necesidad de respetar los envíos acordados y evitar la aparición de movimientos territoriales insolidarios. Las aguas catalogadas de extraordinarias y otros recursos son alterables y de reducida magnitud para el conjunto. Estas han servido para paliar situaciones de necesidad y solo se han efectuado acuerdos de intercambio de aguas o cesiones de derechos cuando era necesario. Estos se utilizaron más durante anteriores sequías y con la llegada de la desalación, se ha optado más por esta fuente para dar respuesta a los abastecimientos ${ }^{31}$. La desalación se ha asentado como un recurso que actúa a modo de seguro hídrico, es decir, produce agua en años de escasez y queda prácticamente inutilizada en años húmedos, aunque la tendencia es de un aumento progresivo motivado por las sequías y la inestabilidad del trasvase Tajo-Segura. La mayor contribución del agua desalada al total distribuido ha tenido como mayor repercusión el aumento del precio del agua, ya que el coste energético es considerablemente mayor para producir agua desalada. También cuenta con detractores que enfatizan en el impacto marino que puede ocasionar la salmuera mal dispersada, o la concentración de boro que la hace inviable para ciertos cultivos. De igual manera, la inver-

Tabla 2. Variación de la participación de cada fuente de suministro en el mix hídrico de la MCT (\%)

\begin{tabular}{lcccc}
\hline PARTICIPACIÓN (\%) & Taibilla & ATS & Otros & Desalación \\
\hline Media '00-'09 & 19,05 & 55,91 & 11,93 & 13,12 \\
Media '10-'19 & 28,75 & 43,22 & 2,39 & 25,64 \\
Media '00-'19 & 23,90 & 49,56 & 7,16 & 19,38 \\
Menor aporte y año & $16,24(2008)$ & $18,74(2017)$ & $0,34(2009)$ & $3,41(2013)^{\star}$ \\
Mayor aporte y año & $39,19(2013)$ & $75,02(2003)$ & $22,46(2002)$ & $47,62(2018)$ \\
\hline
\end{tabular}

*Excluyendo 2000-2003, años de inexistencia o puesta de inicio de la desalación. Fuente: elaboración propia a partir de MCT (2020).

\footnotetext{
31. Gil-Meseguer, Bernabé-Crespo y Gómez-Espín, 2020.
} 
sión pública en plantas desaladoras es esporádicamente cuestionada por la sociedad, que se ha encontrado, en ocasiones, asociada a prácticas de corrupción.

Por último, cabe destacar el papel de la distribución en baja. Son las empresas municipales las que reciben el agua de la MCT y las que la hacen llegar a los usuarios. Por tanto, su labor es fundamental en cuanto a reducir pérdidas y mejorar el rendimiento: tratar de que la distribución en alta sea lo más semejante posible al consumo real ejercido por la población. La actuación de las empresas varía según los municipios y sus características, y se encuentran áreas donde más del $50 \%$ del agua es perdida en red, y otras donde el rendimiento es superior al $80 \%$, como Cartagena ${ }^{32}$. Si bien los datos advierten que se ha avanzado en la reducción del consumo, esta es desigual territorialmente y deben realizarse mejoras en aquellos municipios con una situación de abastecimiento más precaria ${ }^{33}$. Una mayor eficiencia en el rendimiento de la red en baja implicaría un descenso del volumen consumido en alta, lo que ayuda a su sostenibilidad. En un contexto de cambio climático y de previsible disminución de los recursos hídricos, es necesario adoptar estrategias sostenibles ambiental y socioeconómicamente que permitan lograr la seguridad hídrica. La reducción de la demanda es clave para alcanzar un aprovechamiento óptimo del recurso, por lo que realizar acciones en este sentido se antoja prioritario. En cuanto a la oferta de recursos, apostar por el reciclaje del agua es estratégicamente importante ${ }^{34}$ : en el marco de los objetivos para mitigar los efectos del cambio climático, la UE ha realizado una apuesta decidida por la economía circular, en la que el agua es un elemento fundamental para el Pacto Verde Europeo 2019-2024 $4^{35}$. La desalación debería considerarse como un recurso garantizador en aquellas situaciones en las que los trasvases no sean capaces de suministrar caudales, por propia insuficiencia. La investigación en técnicas de desalación que impliquen una menor huella de carbono es indispensable para hacer más sostenibles sus caudales generados.

\section{Conclusiones}

La gestión de los recursos hídricos realizada por la Mancomunidad de Canales del Taibilla en el sureste de España, una región con escasez estructural de agua, ha permitido asegurar un correcto abastecimiento y aumentar la seguridad hídrica para su población y actividades económicas. El análisis de la evolución en la distribución en alta ha mostrado que, a pesar de un incremento de población en el siglo XXI y la creciente llegada de turistas, el volumen consumido ha sido menor que a principios de la serie estudiada. Esto sugiere que se han realizado trabajos de mejora en la eficiencia del recurso y de la red de distribución, minimizando pérdidas y alcanzando rendimientos más elevados, al igual que una concienciación socioambiental que apremia el ahorro de agua.

La tendencia del consumo ha sido positiva de 2000 a 2005; negativa de 2007 a 2014; y se ha vuelto a reactivar desde 2014 hasta la actualidad. Además de la mejora en la eficiencia de la red y la sensibilización social, se apunta a la crisis económica como factor que repercute en el consumo de agua: afluencia de visitantes y apertura o cierre de establecimientos de la industria turística. En los próximos años cabría esperar la continuación de la tendencia al alza en el consumo, aunque no debería sobrepasar el umbral precrisis y emplear medidas de ahorro doméstico y turístico más eficaces.

El río Taibilla aporta un caudal relativamente regular, pero reducido, al mix hídrico de la MCT, que solo depende de la precipitación. Este suele aportar, de media, un $24 \%$ del total. La desviación típica de sus aportes es de $\sigma=18,70 \%$ de su aportación media en el periodo 2000-2019, que se sitúa en $48.061 .879 \mathrm{~m}^{3}$ al año.

El agua procedente del trasvase Tajo-Segura ha sufrido una variación en sus aportes al mix hídrico, pues en la segunda década del siglo XXI sus aportes han sido considerablemente menores. El trasvase suele aportar un $50 \%$ del total y su desviación típica es de $\sigma=29,38$ $\%$ de los aportes medios, que son $101.426 .507 \mathrm{~m}^{3}$. La reducción de las precipitaciones ha motivado el cierre del trasvase durante siete meses entre 2017 y 2018, y las tensiones interterritoriales entre las diferentes Comunidades Autónomas cuestionan el normal funcionamiento del acueducto cuando las reservas hídricas lo permitan. Resulta necesario llegar a acuerdos que permitan el mantenimiento de esta estructura, siempre que la situación hidráulica lo permita, ya que es clave en el abastecimiento de agua potable para una región

\footnotetext{
32. Bernabé-Crespo y Gómez-Espín, 2015.

33. Bernabé-Crespo, Tudela y Gómez-Espín, 2021.

34. Sgroi, Vagliasindi y Roccaro, 2018.

35. EEA, 2016; Comisión Europea, 2020.
} 
donde viven más de 2,5 millones de personas permanentemente y otros millones más de visitantes.

El agua procedente de recursos extraordinarios y contratos de cesión de derechos al uso de agua representa un porcentaje residual y que solo se ha aplicado en situaciones de carestía. De media para el periodo estudiado, han aportado un $7 \%$ del total y presentan una desviación típica anormal, de más del $104 \%$ de sus aportes medios. Esto indica que dependen de la coyuntura ambiental y socioeconómica para ser puestos en marcha, y son recursos de extrema necesidad. Además, la tendencia parece indicar que están siendo sustituidos por los aportes de la desalación. Aquí se produce un debate entre la conveniencia o no de facilitar los acuerdos mediante contratos y cesiones, los cuales pueden incentivar a sus gestores para lograr una mejor eficiencia del recurso. Sin embargo, se incentiva de igual manera en la desalación, sobre todo en años de sequía donde se produce una alta competencia entre la MCT y los regantes por la firma de contratos con las desaladoras de ACUAMED.

La desalación comenzó a funcionar en el sureste en 2003 y, desde entonces, actúa de manera variable, dependiendo de la necesidad de agua y mayor o menor aporte de las aguas superficiales. De media, teóricamente aporta un $19 \%$, aunque este puede llegar a alcanzar casi un $50 \%$ en un año seco o en torno al $3 \%$ en un año húmedo. Por tanto, su desviación típica es alta, de $\sigma=$ $64,81 \%$ de su aportación media. Atendiendo al desglose por plantas desaladoras, la de San Pedro I es la que más agua ha producido, seguida de Alicante I. En general, se observa que los mayores caudales proceden de las desaladoras de la MCT, y que, cuando es necesario (normalmente, cuando la producción alcanza los $60 \mathrm{mi}-$ llones de $\mathrm{m}^{3}$ anuales), se procede al establecimiento de acuerdos con ACUAMED para suministrar agua desde otras plantas desaladoras. En este último caso, las que más agua han aportado han sido Torrevieja y Valdelentisco. La irrupción de la desalación ha supuesto la garantía de suministro para la población y actividades económicas, incluso en el periodo estival de alta deman$\mathrm{da}$, y el alivio de la competencia por los usos del agua de determinados sectores productivos. Pero también ha implicado la subida del precio del agua debido a su mayor coste energético, así como una inversión pública e impacto ambiental -temas a veces cuestionados por la sociedad-, y su limitación para ciertas actividades, como la presencia del ion boro. Las concentraciones de este elemento dependen, en buena parte, de la temperatura del agua captada, la cual influye en la efectividad de la membrana de ósmosis inversa. El agua desalada debe cumplir las recomendaciones de la OMS para el consumo humano, pero los regantes han comprobado que ciertos cultivos -como los cítricos- no toleran bien su uso, por lo que deben mezclarla con la procedente de otras fuentes.

Garantizar un suministro de agua potable continuo durante el año es clave para el desarrollo socioeconómico de una región donde el agua es un bien muy preciado y valorado. No solo porque es vital para los habitantes del sureste, también para permitir la actividad turística que cada vez atrae a más visitantes y que se suele concentrar de forma masiva en pocos meses del año. Urge tomar medidas de mejora de la red de distribución en las empresas de distribución en baja, lograr un consumo responsable en los propios domicilios, e instalar medidas estratégicas de ahorro en establecimientos turísticos; con el fin de continuar la senda de contracción del consumo per cápita y evitar un nuevo aumento por encima de los niveles precrisis económica. De igual manera, es primordial asegurar y mantener la diversificación de la oferta del recurso conseguida en el siglo XXI: aguas superficiales, trasvasadas y desaladas, acompañadas de una mayor flexibilidad burocrática para poder ejercer contratos de cesiones de derechos si estos son necesarios, al igual que para las plantas desaladoras. El mantenimiento del trasvase Tajo-Segura debe ser consensuado y no debe ser objeto de tensiones interterritoriales, debiendo su supervivencia únicamente a características ambientales y a la situación de reserva hidráulica. Por su parte, la desalación necesitaría de mejoras en cuanto a la investigación en I+D+i para conseguir reducir costes de producción y poder abaratar un agua encarecida, pero necesaria. El agua desalada es un "agua segura" en su doble sentido: segura para su consumo y asegurada para su distribución, pero su mayor precio compromete su rentabilidad. Es necesario invertir en la investigación para tratar de economizar este recurso y, no menos importante, hallar técnicas que reduzcan su huella de carbono para hacerla más sostenible. De igual manera, es urgente estudiar los efectos en el medio marino y buscar su mejor emplazamiento, así como realizar un control sobre su gestión y trasladar a la sociedad la necesidad de inversión en una infraestructura que se ha posicionado como clave dentro del abastecimiento mediterráneo.

La correcta planificación de los recursos hídricos debe prever el efecto del cambio climático y buscar una solución sostenible ambiental, social y económicamente. La diversificación de la oferta de recursos debe 
extender el reciclaje de aguas a aquellos lugares donde no se realice e indagar sobre su reutilización potable. El mantenimiento del ATS debe continuar siempre que la situación lo permita, a la misma vez que realizar avances en la desalación, por las razones anteriormente citadas. Se debe comenzar por lo inmediato, y es gestionar la demanda, entre lo que sobresale mejorar la red de distribución para lograr la eficiencia y promover un uso responsable del agua, que tanto ha costado disponer en estas tierras del sureste español.

\section{BIBLIOGRAFÍA}

Baños, C. J., Vera, J. F. y Díez, D. 2010: "El abastecimiento de agua en los espacios y destinos turísticos de Alicante y Murcia". Investigaciones Geográficas, 51, 81-105. https://doi. org/10.14198/INGE02010.51.04

Bates, B., Kundzewicz, Z. W., Wu, S. \& Palutikof, J. (Eds.) 2008: Climate change and water. Technical Paper of the Intergovernmental Panel on Climate Change. Geneva (Switzerland), IPCC Secretariat.

Bernabé-Crespo, M. B. 2020: Los canales del agua: abastecimiento y saneamiento en la comarca del Campo de Cartagena-Mar Menor. Madrid (España), Ministerio para la Transición Ecológica y el Reto Demográfico y Mancomunidad de Canales del Taibilla.

Bernabé-Crespo, M. B., Gil-Meseguer, E. y Gómez-Espín, J. M. 2019: "Desalination and water security in Southeastern Spain". Journal of Political Ecology, 26 (1), 486-499. https://doi. org/10.2458/v26i7.22911

Bernabé-Crespo, M. B. y Gómez-Espín, J. M. 2015: "El abastecimiento de agua a Cartagena". Cuadernos geográficos, 54 (2), 270-297. https://doi.org/10.30827/cuadgeo.v54i2.3097

Bernabé-Crespo, M. B. y Loáiciga, H. A. 2019: "El suministro hídrico a la aglomeración urbana de Los Ángeles, California (EEUU)". Agua y Territorio, (13), 35-42. https://doi.org/10.17561/ at.73.3789

Bernabé-Crespo, M. B., Tudela Serrano, M. L. y Gómez-Espín, J. M. 2021: "Gestión del abastecimiento de agua en una región semiárida: análisis del consumo de agua potable en el Campo de Cartagena-Mar Menor: 2010-2019". Boletín de la Asociación Española de Geografía, 88. https://doi.org/10.21138/bage.3009

Campos, H. L. y Pacheco, S. M. 2018: "Un análisis histórico y geográfico de la importancia del río Beberibe para el suministro de agua de la Región Metropolitana de Recife". Agua y Territorio, 11, 34-43. https://doi.org/10.17561/at.11.2945

Comisión Europea. 2020: Comunicación de la Comisión al Parlamento Europeo, al Consejo Europeo, al Consejo, al Comité Económico y Social Europeo y al Comité de las Regiones: El Pacto Verde Europeo. Bruselas (Bélgica), COM/(2019)/640 Final.
Cooley, H., Gleick, P. \& Wolff, G. 2006: Desalination, with a Grain of Salt: Perspectives from California. Berkeley (California), Pacific Institute.

EEA (European Environment Agency). 2016: Circular Economy in Europe - Developing the knowledge base. EEA Report No. 2/2016. $42 \mathrm{p}$.

Gil-Meseguer, E. 2019: "Trasvases de agua al sureste de España". Agua y Territorio, (13), 55-68. https://doi.org/10.17561/at.13.4421

Gil-Meseguer, E., Bernabé-Crespo, M. B. y Gómez-Espín, J. M. 2017: "Las políticas de trasvases de agua y desalación en España, sus repercusiones en la ordenación del territorio del Sureste". Actas del XXV Congreso de la AGE "50 años de congresos de Geografía. Naturaleza, territorio y ciudad en un mundo global". Madrid (España), Asociación de Geógrafos Españoles (AGE) y Universidad Autónoma de Madrid, 2.480-2.489. https://doi.org/10.15366/ ntc. 2017

Gil-Meseguer, E., Bernabé-Crespo, M. B. y Gómez-Espín, J. M. 2019: "Recycled sewage - A water resource for dry regions of Southeastern Spain". Water Resources Management, 33 (2), 725-737. https://doi.org/10.1007/s11269-018-2136-9

Gil-Meseguer, E., Bernabé-Crespo, M. B. y Gómez-Espín, J. M. 2020: "Resiliencia en el consumo de agua por parte de abastecimientos y regadíos ante las sequías en el Sureste de España". Cuadernos de Geografía, 104, 107-130. https://doi.org/10.7203/ CGUV.104.16328

Gil-Meseguer, E., García Martínez, P. J., Gómez-Espín, J. M. y Almela Pérez, R. 2014: El dinamismo del regadío de Pulpí. Murcia (España), C. R. Pulpí.

Gil-Meseguer, E. y Gómez-Espín, J. M. 2017: El trasvase de aguas del embalse del Negratín (Granada) al embalse de Cuevas del Almanzora (Almería). La Conexión Negratín-Almanzora (C $N-A)$. Murcia (España), Colección Usos de agua en el territorio, Universidad de Murcia y AGUAS DEL ALMANZORA, S. A.

Gil-Meseguer, E., Martínez-Medina, R. y Gómez-Espín, J. M. 2018: "El trasvase Tajo-Segura (1979-2017). Actuaciones para su futuro en España". Tecnología y Ciencias del Agua, 9 (2), 160174. https://doi.org/10.24850/j-tyca-2018-02-08

Gleick, P. 2010: "Roadmap for sustainable water resources in southwestern North America". Proceedings of the National Academy of Sciences (PNAS), 107 (50), 21.300-21.305. https://doi. org/10.1073/pnas. 1005473107

Gómez, C. M. 2018: "La seguridad hídrica como envolvente". En Delacámara, G., Lombardo, F. y Díez, J. C. (Coord.), Libro blanco de la economía del agua. Madrid (España), McGraw-Hill Interamericana de España, 5-12.

Gómez-Espín, J. M., López-Fernández, J. A. y Montaner, E. (Coord.). 2011: Modernización de regadíos: sostenibilidad social y económica. La singularidad de los regadíos del Trasvase TajoSegura. Murcia (España), Colección Usos de agua en el territorio, Universidad de Murcia. 
González-Morales, A. y Ramón-0jeda, A. 2019: "La desalación de agua de mar en las Canarias Orientales: los casos de Lanzarote y Fuerteventura". Agua y Territorio, (13), 15-26. https://doi. org/10.17561/at.13.3722

Hamrita, A. y Rejeb, H. 2019: "Futuro de la gestión integrada "aguas residuales tratadas/agricultura periurbana" en Túnez. Caso del perímetro de riego público (PRP) de Zaouia (Susa)". Agua y Territorio, 13, 27-34. https://doi.org/10.17561/at.13.4115

Juárez, C. 2008: "Indicadores hídricos de sostenibilidad y desarrollo turístico y residencial en la Costa Blanca (Alicante)". Boletín de la Asociación de Geógrafos Españoles, 47, 213-243.

Loáiciga, H. A. 2015: "Managing municipal water supply and use in water-starved regions: Looking ahead". Journal of Water Resources Planning and Management, 141 (1), 01814003/1-4. https://doi.org/10.1061/(ASCE)WR.1943-5452.0000487

March, H. 2015: "The politics, geography, and economics of desalination: a critical review". WIREs Water, 2, 231-243. https://doi. org/10.1002/wat2.1073

Martínez del Vas, G. 2017: "Proceso de configuración de un destino turístico y efectos de la política turística en la Región de Murcia". Cuadernos de Turismo, 40, 439-464. https://doi. org/10.6018/turismo.40.310061

Mballa, L. V. y Hernández-Espericueta, F. 2018: "Las políticas públicas de abastecimiento de agua potable y saneamiento para la localidad de Escalerillas, San Luis Potosí - México: escenarios y percepción ciudadana". Agua y Territorio, (11), 137-152. https://doi.org/10.17561/at.11.3378

McEvoy, J. \& Wilder, M. 2012: "Discourse and desalination: Potential impacts of proposed climate change adaptation interventions in the Arizona-Sonora border region". Global Environmental Change, 22, 353-363. https://doi.org/10.1016/j.gloenvcha.2011.11.001

Mediavilla, J. 1928: Cartagena y las aguas de la Región Murciana. Tomos II y III. Cartagena (España), Casa Garnero.

Melgarejo, J. y Molina, A. 2017: La Mancomunidad de los Canales del Taibilla en la provincia de Alicante. Análisis de la implantación y evolución de la Mancomunidad de los Canales del Taibilla en la provincia de Alicante y sus repercusiones. Cartagena (España), Mancomunidad de los Canales del Taibilla e Instituto Universitario del Agua y de las Ciencias Ambientales. https://doi. org/10.14198/2017-Mancomunidad-Canales-Taibilla

Ministerio de Obras Públicas. Dirección General de Obras Hidráulicas. 1967: Anteproyecto General de Aprovechamiento Conjunto de los Recursos Hidráulicos del Centro y Sureste de España. Complejo Tajo-Segural. Noviembre de 1967. MOP. Madrid. Tomo I 230 pp. Tomo II 294 pp. + 67 planos. (Ingenieros J. Ma Martín Mendiluce y J. Ma. Pliego Gutierrez).

Morales, A. y Vera, F. 1989: La Mancomunidad de los Canales del Taibilla. Influencia de un gran sistema de abastecimiento público de aguas en el desarrollo económico territorial. Murcia (España), Academia Alfonso X El Sabio.
Morote, A. F., Hernández, M. y Lois, R. C. 2019: "Propuestas al déficit hídrico en la provincia de Alicante: medidas desde la gestión de la demanda y oferta de recursos hídricos". Boletín de la Asociación de Geógrafos Españoles, 80, 1-48. https://doi. org/10.21138/bage.2655

Morote, A. F., Olcina, J. y Rico, A. M. 2018: "Un trasvase cuestionado: El Tajo-Segura. Repercusiones socio-económicas en el sureste español e incertidumbre ante el cambio climático". Revista de Estudios Regionales, 113, 29-70.

Morote, A. F., Rico, A. M. \& Moltó, E. 2017: "Critical review of desalination in Spain: a resource for the future?" Geographical Research, 55 (4), 412-423. https://doi.org/10.1111/1745-5871.12232

Nieto, A. 2013: El sueño se hace realidad (1939-1964). Cartagena (España), Mancomunidad de los Canales del Taibilla.

Olcina, J. 2012: "Turismo y cambio climático: una actividad vulnerable que debe adaptarse". Investigaciones Turísticas, 4, 1-34. https://doi.org/10.14198/INTURI2012.4.01

Olcina, J. y Moltó, E. 2010: "Recursos de agua no convencionales en España: estado de la cuestión". Investigaciones Geográficas, 51, 131-163. https://doi.org/10.14198/INGE02010.51.06

Olcina, J., Saurí, D. y Vera, J. F. 2016: "Turismo, cambio climático y agua: escenarios de adaptación en la costa Mediterránea española". En Olcina, J., Saurí, D. y Vera Rebollo, J. F. (Coords.), Libro Jubilar en Homenaje al Profesor Antonio Gil Olcina. Alicante (España), Universidad de Alicante, 171-193. https://doi. org/10.14198/LibroHomenajeAntonioGilOlcina2016-13

OMS. 2018: Guías para la calidad del agua de consumo humano. Disponible en: https://www.who.int/es/publications/i/ item/9789241549950

Rico Amorós, A. M. 2007: "Tipologías de consumo de agua en abastecimientos urbano-turísticos de la Comunidad Valenciana". Investigaciones Geográficas, 42, 5-34. https://doi.org/10.14198/ INGE02007.42.01

Rutherfurd, I. \& Finlayson, B. 2011: "Whither Australia: Will availability of water constrain the growth of Australia's population?" Geographical Research, 49 (3), 301-316. https://doi.org/10.1111/ j.1745-5871.2011.00707.x

Sgroi, M., Vagliasindi, F. \& Roccaro, P. 2018: "Feasibility, sustainability and circular economy concepts in water reuse". Current Opinion in Environmental Science and Health, 2, 20-25. https:// doi.org/10.1016/j.coesh.2018.01.004

Vera, J. F. 2006: "Agua y modelos de desarrollo turístico: la necesidad de nuevos criterios para la gestión de los recursos". Boletín de la Asociación de Geógrafos Españoles, 42, 155-178.

Vera, F. y Morales, A. 1989: "Ordenación y gestión de recursos hídricos en un ámbito subárido: el abastecimiento de los municipios integrados en la Mancomunidad de los Canales del Taibilla". Investigaciones geográficas, 7, 51-68. https://doi.org/10.14198/ INGE01989.07.16 